\title{
Microbiota of Exposed Root Surfaces After Fluoride, Chlorhexidine, and Periodontal Maintenance Therapy: A 3-Year Evaluation
}

\author{
Mozhgan Bizhang, ${ }^{*}$ Yong-Hee P. Chun, ${ }^{\dagger}$ Doreen Heisrath,${ }^{\ddagger}$ Peter Purucker, $§$ Preeti Singh,॥
} Thomas Kersten, ${ }^{\ddagger}$ and Stefan Zimmer

Background: Fluoride and chlorhexidine (CHX) are stateof-the-art preventive measures for remineralizing teeth and for preventing plaque accumulation. The aim of this study was to examine the effects of fluoride and $\mathrm{CHX}$ varnishes on root caries and microbiota located on root surfaces.

Methods: Thirty-three patients from a periodontal maintenance program, having at least one tooth with gingival recession in each quadrant, participated in this study. One tooth per quadrant was assigned randomly to the control group or to one of the test groups that were treated with fluoride varnish, $1 \%$ CHX, or $40 \%$ CHX. The varnish treatment and the tooth cleaning were repeated every 3 months. Clinical examinations were performed at baseline and once a year for 3 years. Caries status and oral hygiene indices were evaluated clinically. The total cultivable microbiota and percentage of Mutans streptococci (MS), Actinomyces (ACC), and lactobacilli ( $L B)$ were analyzed.

Results: Oral hygiene was improved greatly during the course of the study. The percentage of MS, ACC, and LB of the total cultivable microbiota revealed a statistically significant reduction between baseline and final examination for each of the four groups.

Conclusion: Professional tooth cleaning alone at 3-month intervals might be as effective in reducing MS, $A C C$, and $L B$ as adjunctive treatment with fluoride or chlorhexidine. $J$ Periodontol 2007;78:1580-1589.

\section{KEY WORDS}

Chlorhexidine; fluoride; microbiology; periodontitis; root caries.

* Department of Operative and Preventive Dentistry and Endodontics, Section of Periodontology, Heinrich-Heine-University, Düsseldorf, Germany.

$\dagger$ Biologic and Materials Sciences, Periodontics and Oral Medicine, University of Michigan, Ann Arbor, MI

‡ Department of Operative and Preventive Dentistry, Charité - University Medical School of Berlin, Berlin, Germany.

$\S$ Department of Periodontics, Charité - University Medical School of Berlin.

|| Department of Operative and Preventive Dentistry and Endodontics, Heinrich-HeineUniversity.
$\mathrm{R}$ oot surface caries is a common problem encountered in dental patients with increasing implications for public health. ${ }^{1}$ The growing geriatric population in many developed countries is expected to retain their teeth into old age. According to epidemiologic studies, root caries is prevalent among patients with treated and untreated periodontal disease. ${ }^{2-4}$ As a direct consequence of periodontal disease or its treatment, the gingiva recedes, displaying the root surfaces supragingivally 5,6 and exposing them to carious insults. Bacterial dental plaque is a key component in the development of root caries.

The etiologic bacteria for initiation and progression of root caries have been investigated. Initially, Actinomyces (ACC) was believed to be the pathogen initiating root caries. ${ }^{7-9}$ More recently, Mutans streptococci (MS) and lactobacilli $(L B)$ also have been considered to contribute to root caries. ${ }^{10-12}$ Collectively, a complex of microbiota may facilitate the pathogenesis of root caries.

Accessibility, root morphology, and the rate of caries progression pose limitations on the therapy of root caries lesions. Therefore, the prevention of root caries is desirable. Fluoride is a well-established preventive measure for root caries and for the reversal of carious initial lesions in general. Many clinical studies have 
validated the application of fluoride in preventing and remineralizing root caries. ${ }^{13-15}$ Another antibacterial agent, chlorhexidine (CHX), is effective in reducing the numbers of $M S$ in dental plaque ${ }^{16-18}$ and in inhibiting the development of fissure caries ${ }^{19}$ when applied to the tooth surfaces as a varnish. Persistent reduction of MS was shown to depend on the CHX concentration. When comparing the effects of $10 \% \mathrm{CHX}, 20 \%$ CHX, and 40\% CHX over 22 weeks, only the $40 \%$ CHX varnish reduced the numbers of MS in fissures. ${ }^{17}$

The aim of this 3-year prospective clinical trial was to examine the effects of fluoride and CHX varnishes on the incidence of root caries and microbiota at root surfaces in periodontitis patients participating in a periodontal maintenance program. The efficacy of the dental varnishes was tested on MS, ACC, and $L B$ growth. The varnishes were reapplied every 3 months during the 3-year study period.

\section{MATERIALS AND METHODS}

For this 3-year study, volunteers were recruited from the Department of Periodontology, Charite - University Medical School of Berlin. Prior to the start of the study in January, 2000, the study design was reviewed and approved by the ethics committee of the Charité - University Medical School of Berlin. All participants gave their informed consent. Thirty-three subjects, $12(36.4 \%)$ males and 21 (63.6\%) females, joined the study. At enrollment, all subjects had received and completed periodontal therapy and had been participating in a periodontal maintenance program for 1 to 18 years. The mean age of the subjects at baseline was $53.99 \pm 8.11$ years, with a range of 37 to 66 years. The current and past prevalence of dental caries was obtained by calculating the number of decayed, missing, filled surfaces (DMFS), and the future risk for caries was estimated by MS levels in saliva using a chair-side saliva test. "I The study subjects demonstrated high past and present caries activity, reflected by a mean DMFS of $69.26 \pm 29.58$, and high levels of MS in saliva, reflected by a score of 3 , corresponding to colony forming unit $(\mathrm{CFU}) / \mathrm{ml}$ saliva $\geq 10^{5}$, on a scale from 1 to 4 .

Inclusion criteria for the subjects were the presence of at least one tooth with gingival recession in each quadrant, a sound and intact root surface at the exposed site, and a recession $\geq 2 \mathrm{~mm}$ from the cemento-enamel junction (CEJ) to the free gingival margin. Further, the subjects were required to be in good general health, to have $\geq 20$ natural teeth, and to have a stimulated saliva secretion rate $\geq 0.7 \mathrm{ml} /$ minute. Exclusion criteria were the use of systemic medication interfering with the condition of periodontal tissues or the risk for caries development, the use of systemic antibiotics or an antibacterial mouthrinse $<2$ months prior to the beginning of the study and prior to each examination, or local application of fluoride or antibacterial agents 3 months prior to the beginning of the study. During the entire study period, two subjects used systemic antibiotics and completed the regimen $>8$ weeks before examination. Four subjects were smokers with an occasional consumption of one to two cigarettes per day.

\section{Plaque Sampling}

Plaque samples were taken after each examination at baseline and after 12, 24, and 36 months (Fig. 1; Table 1). Prior to collecting the plaque, the subjects received a professional teeth cleaning and were asked to refrain from brushing their teeth. Plaque was allowed to accumulate for $48 \pm 2$ hours to obtain mature plaque in a standardized manner. ${ }^{20}$ Plaque samples were collected from test and control teeth that had been isolated with cotton rolls and dried. Only facial surfaces were sampled. ${ }^{21}$ The supragingival samples were taken with a sterile Gracey curet, " which was run from the mesial to the distal side of the root surface. An effort was made not to touch the gingiva with the curet. Plaque samples were dispersed in $1 \mathrm{ml}$ cold $\left(6^{\circ} \mathrm{C}\right.$ to $\left.8^{\circ} \mathrm{C}\right)$ reduced transport fluid (RTF; $0.6 \%$ $\mathrm{K}_{2} \mathrm{HPO}_{4}, 1.2 \% \mathrm{NaCl}, 1.2 \%\left(\mathrm{NH}_{4}\right) 3 \mathrm{SO}_{4}, 0.6 \% \mathrm{KH}_{2} \mathrm{PO}_{4}$ $0.25 \% \mathrm{MgSO}_{4}, 0.1 \mathrm{M}$ EDTA, $8 \% \mathrm{Na}_{2} \mathrm{CO}_{3}, 1 \%$ dithiothreitol, $0.1 \%$ resazurin, and distilled water $)^{22}$ serially diluted to 1:10 in RTF and transported immediately to the microbiology laboratory. One plaque sample was obtained from each tooth and analyzed individually. After obtaining and processing the plaque samples, all teeth were cleaned and polished. In the laboratory, the plaque sample was examined first under a light microscope. Aliquots of adequate dilutions (serial dilutions of $1: 100,1: 10,000$, and $1: 1,000,000)$ were plated on different agars and cultured under anaerobic conditions at $35^{\circ} \mathrm{C}$ to $37^{\circ} \mathrm{C}$. After 7 days, CFUs were counted using a stereomicroscope at magnifications of $\times 10$ to $\times 15$. Brain heart infusion agar supplemented with $5 \%$ defibrinated sheep blood ${ }^{* *}$ was used for total anaerobic bacterial counts. The species of the bacteria were determined by growth on selective media: $L B$ on modified Rogosa agar, ${ }^{\dagger \dagger}$ ACC on cadmium fluoride acriflavin tellurite (CFAT) agar, ${ }^{\ddagger} 23$ and MS on mitis salivarius agar. ${ }^{\$ 24}$ We determined the proportion of each organism relative to the total cultivable microbiota. Total counts for each bacterial species grown on the selective agar were expressed as a percentage of the total number of colonies. All bacteriologic analyses were performed by TK.

\footnotetext{
I CRT - Caries Risk Test, Vivadent-Vivacare, Schaan, Liechtenstein. \# Hu-Friedy, Chicago, IL.

** BAG, Lich, Germany.

$\dagger \dagger$ Heipha Diagnostika, Heidelberg, Germany.

㚘 BAG.

$\S \S$ BAG.
} 


\section{Clinical Examination}

Clinical examination was performed $48 \pm 2$ hours before the bacteriologic sampling. To avoid interexaminer differences, all examination procedures and varnish applications were performed by the same experienced clinician (DH). Therefore, the clinical procedures were not blinded. Prior to the study, the clinician was calibrated on a series of patients to ensure validity of the clinical measurements. Plaque records were assessed according to the approximal plaque index (API; scored according to Lange et al. ${ }^{25}$ ) and plaque index (modified Quigley and Hein in$\operatorname{dex}^{26}[\mathrm{QHI}]$ scored according to Turesky et al.). Gingivitis was recorded using the papillary bleeding index (PBI; scored according to the criteria of Saxer and Mühlemann ${ }^{27}$ ). API, QHI, and PBI were recorded $48 \pm 2$ hours before collecting the plaque. The gingival recession or hyperplasia was measured clinically at four sites per tooth, two sites facially and two sites lingually, with a University of North Carolina periodontal probe lll| as the distance between the free gingival margin and the CEJ. Root caries was recorded on exposed facial root surfaces at baseline and after 12,24 , and 36 months. Concurrently, the texture and color of the lesion were recorded. Apparent lesions were judged as active when greasy, yellowish or light brownish, and soft on light probing. Inactive lesions were assumed when the color was brownish tan or dark, smooth, and sound on probing. ${ }^{28}$ If root caries developed during the study period, the study protocol included adequate rescue therapy of the lesion. Clinical and microbiologic examinations were performed at baseline $\left(E_{0}\right)$ and after $12\left(E_{1}\right), 24\left(E_{2}\right)$, and 36 months $\left(E_{3}\right)$.

\section{Treatment}

For each subject, the qualifying tooth from each quadrant was assigned to the control group (group A) or to one of the test groups (groups B through D). The assignment of quadrants and tooth type (incisor, premolar, and molar) to the various groups was performed using a randomization list. All subjects used

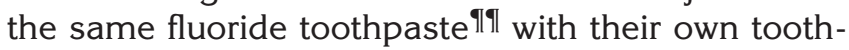
brush and interdental brush throughout the study period of 3 years. The subjects were discouraged from using an antibacterial mouthrinse during the study period. If a pocket displayed bleeding on probing, the pocket was scaled and root planed thoroughly prior to the professional teeth cleaning (Fig. 1). In addition, oral hygiene instructions were given to the participants. In the event of generalized recurrent periodontitis, the study protocol included removing the patient from the study and providing rescue periodontal therapy. Supportive periodontal treatment was performed for all subjects at 3-month intervals, for a total of 13 sessions of teeth cleaning, flossing, oral hygiene in- structions, and varnish application (Table 1; Fig. 1). All subjects received the same program.

The varnish was applied to the root surface every 3 months after teeth cleaning and polishing with a fluoride-containing paste (Table 1), either at bacteriologic sampling or at maintenance-only sessions. The teeth receiving the varnish were isolated with cotton rolls quadrant-by-quadrant and dried with an air syringe; the respective agents were applied with a disposable microbrush. Teeth in the control group (group A) were polished with a fluoride paste (Fig. 1). Teeth of group B were treated with fluoride varnish,"\# teeth of group $\mathrm{C}$ were treated with $1 \% \mathrm{CHX}^{* * *}$ varnish, and teeth of group D were treated with $40 \%$ CHX. ${ }^{\dagger \dagger}$ According to the manufacturer's instructions, the $40 \%$ CHX varnish was left in place for $8 \mathrm{~min}$ utes and then removed with a rubber cup, polishing paste, and dental floss. The subjects were instructed to avoid beverages or food for 4 hours after the fluoride varnish application and for 2 hours after the $1 \%$ CHX application; only water was allowed after 1 hour. Diet was not restricted following the application of the $40 \%$ CHX, according to the manufacturer's instructions.

\section{Data Analysis}

All statistical analyses were performed with a statistical program. ${ }^{\neq \neq} \neq$The distributions were analyzed using the Kolmogorov-Smirnov test. Data analysis was accomplished using the non-parametric Friedman and Wilcoxon tests. The dependent variable was the change in the bacteriologic counts compared to baseline. The tests were performed with $\alpha=0.05$ to test for significant differences between baseline and annual examinations $\left(E_{1}\right.$ through $\left.E_{3}\right)$ and between the groups (A through D).

\section{RESULTS}

Thirty-three subjects entered the study, and 29 patients completed the study. The absolute dropout rate was $6.0 \%$ (two patients) after 1 year, $9.0 \%$ (three patients) after 2 years, and $12.1 \%$ (four patients) after 3 years. Teeth distribution among the four groups was as follows: group A: 25 incisors, three premolars, and one molar; group B: 24 incisors, four premolars, and one molar; group C: 26 incisors and three premolars; and group D: 25 incisors, three premolars, and one molar.

Data regarding PBI, QHI, API, total cultivable microbiota, and percentage CFUs of MS, ACC, and $L B$ were not distributed normally (Kolmogorov-Smirnov test).

\footnotetext{
||| Hu-Friedy.

ๆ| Elmex sensitive, GABA, Basel, Switzerland.

\#\# Duraphat; $2.26 \%$ sodium fluoride; Colgate-Palmolive, Piscataway, NJ

$* * *$ Cervitec; $1 \%$ chlorhexidine and $1 \%$ thymol; Vivadent-Vivacare.

$\dagger \dagger \dagger$ EC 40; 40\% chlorhexidine; Explore, Nijmegen, The Netherlands.

$\neq \neq \neq$ SPSS, version 12 .0 for Windows, SPSS, Chicago, IL.
} 


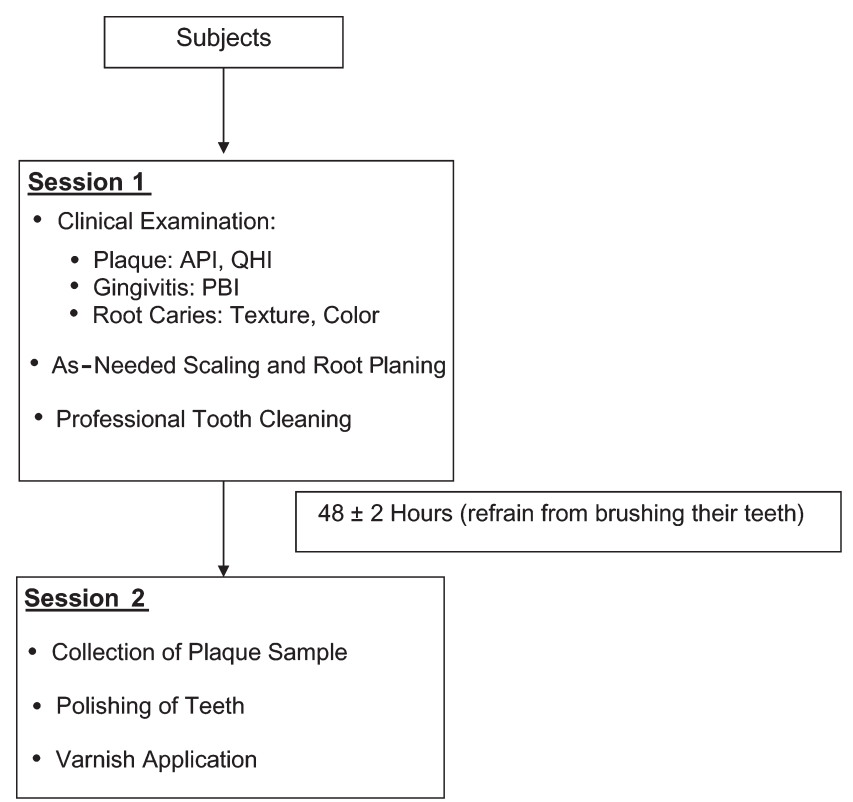

Figure I.

Sequence of the clinical examination, plaque sampling, and intervention.

Table I.

\section{Outline of Study Design}

\begin{tabular}{|c|c|c|c|c|c|c|c|c|c|c|c|c|c|}
\hline & \multicolumn{13}{|c|}{ Months } \\
\hline & 0 & 3 & 6 & 91 & 121 & 151 & 182 & 212 & 24 & 273 & 30 & 33 & 36 \\
\hline Examination & $E_{0}$ & & & & $E_{1}$ & & & & $E_{2}$ & & & & $E_{3}$ \\
\hline Plaque sample & $x$ & & & & $x$ & & & & $x$ & & & & $x$ \\
\hline $\begin{array}{l}\text { Periodontal } \\
\text { maintenance }\end{array}$ & $x$ & $x$ & $x>$ & $x>$ & $\times>$ & $x$ & $\times>$ & $x$ & $x$ & $x$ & $x$ & $x$ & $x$ \\
\hline Varnish & $x$ & $x$ & $x>$ & $x>$ & $x>$ & $\times>$ & $x>$ & $x$ & $x$ & $x$ & $x$ & $x$ & $x$ \\
\hline
\end{tabular}

$\mathrm{X}=$ dental visit.

\section{Gingival Status}

The PBI at the baseline examination was significantly higher than the PBI at the final examination after 3 years (Friedman and Wilcoxon tests) (Fig. 2).

\section{Plaque Status}

The analysis of plaque accumulation at the end of the study showed that the API and QHI had decreased over the 3-year study period. The differences were statistically significant between baseline and final examination (Friedman and Wilcoxon tests) (Figs. 3 and 4).

\section{Caries and Recessions}

No new carious root surface lesions were detected at the study teeth. The amount of recession did not change significantly during the study.

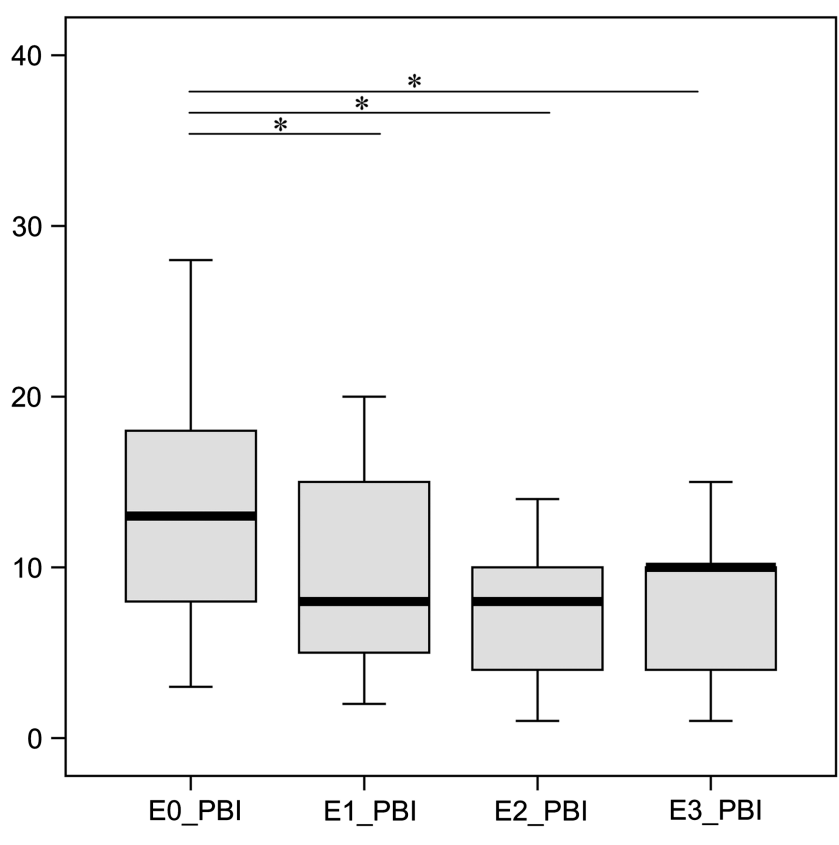

Figure 2.

$P B \mid$ at baseline (EO_PBI) and after I (EI_PBI), 2 (E2_PBI), and 3 years $\left(E 3 \_P B I\right)$. $* P<0.01$.

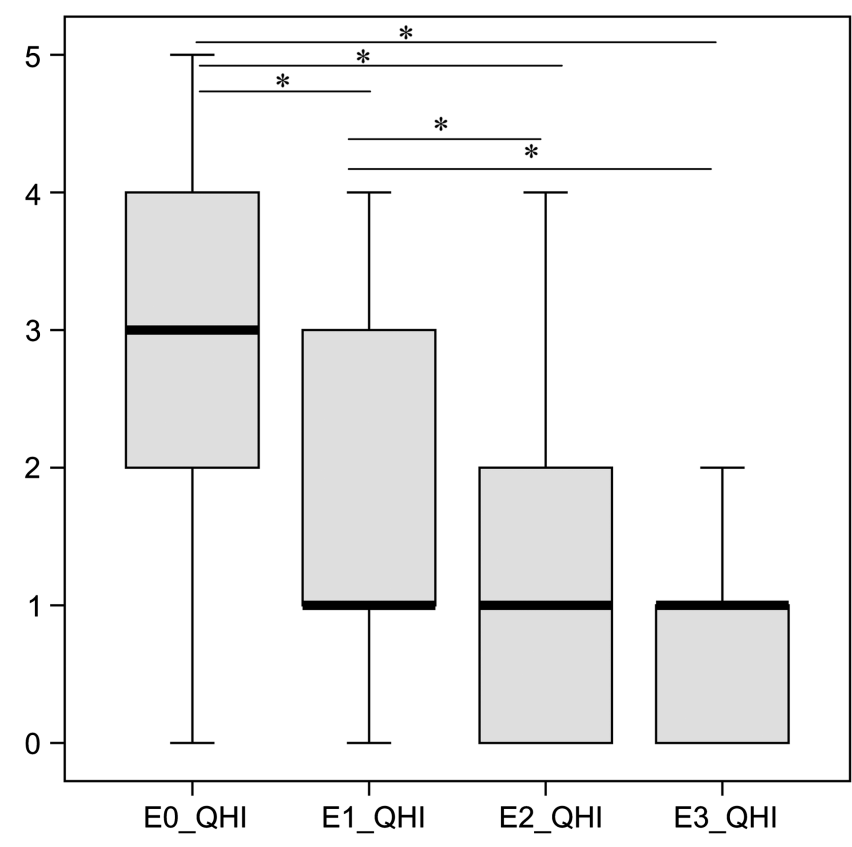

Figure 3.

QHI at baseline (EO_QHI) and after I (EI_QHI), 2 (E2_QHI), and 3 years (E3_QHI). $* P<0.01$.

\section{Plaque Samples}

The Friedman test revealed no significant differences in the number of total cultivable microbiota during the experimental period for all four groups. 


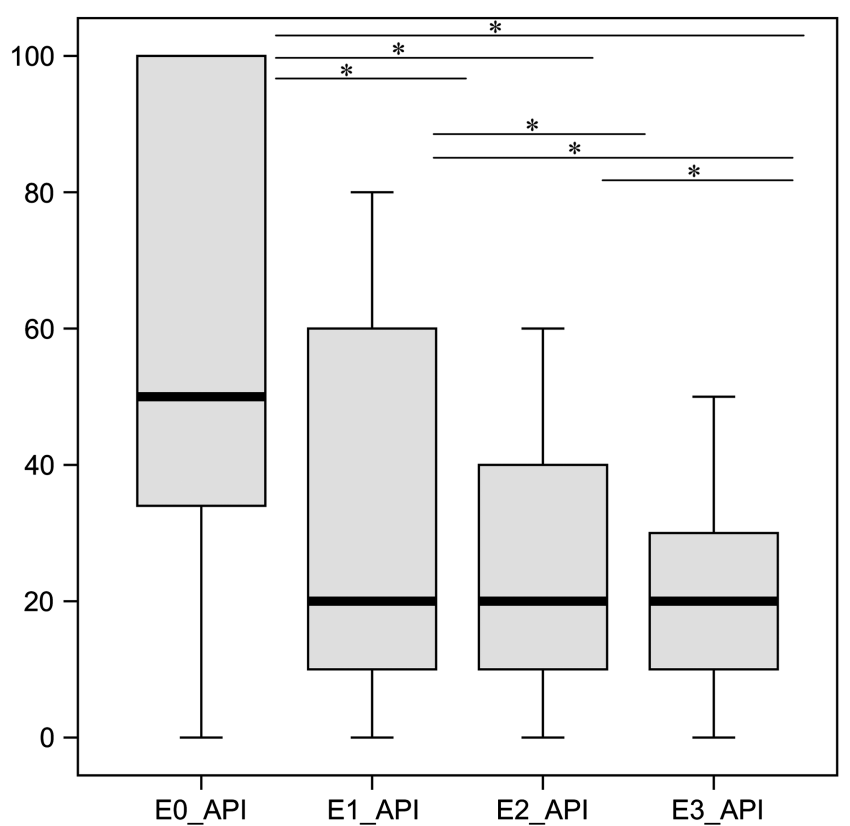

Figure 4

API at baseline (EO_API) and after I (EI_API), 2 (E2_API), and 3 years (E3_API). $*$ P $<0.01$.

The data for MS, ACC, and $L B$ were analyzed as a percentage of the total cultivable microbiota and are presented as median, maximum, minimum, and $25 \%$ and $75 \%$ percentiles in Tables 2 through 4 . The median was used because the data were not distributed normally. Significant differences were found within the groups for the percentages of MS, ACC, and $L B$ of the total cultivable microbiota. The percentages of MS, ACC, and $L B$ of the total cultivable microbiota from root surfaces were significantly higher at baseline compared to examinations $E_{2}$ and $E_{3}$ in all four groups (Tables 2 through 4).

Regardless of the CHX concentration, the percentage of $M S$ of total cultivable microbiota following treatment did not differ statistically from any other treatment. However, the percentage of ACC of total cultivable microbiota was significantly lower in the $1 \%$ CHX group than in the control or fluoride varnish group. In the $40 \%$ CHX group, the cultivable microbiota was significantly lower than in the control group but not significantly lower than the fluoride varnish group. The percentage of $L B$ did not show any statistically significant difference between the four groups (Figs. 5 through 7).

\section{DISCUSSION}

As a direct consequence of periodontal disease or its treatment, the gingiva recedes, displaying the root
Table 2.

\section{Percentage of MS of Total Cultivable Microbiota}

\begin{tabular}{|c|c|c|c|c|c|}
\hline MS & Minimum & Maximum & Median & $\begin{array}{c}25 \% \\
\text { Percentile }\end{array}$ & $\begin{array}{c}75 \% \\
\text { Percentile }\end{array}$ \\
\hline \multicolumn{6}{|c|}{ Group A: control } \\
\hline$E_{0}$ & 0.02 & 30.90 & $4.40^{a, b}$ & 1.35 & 14.38 \\
\hline$E_{1}$ & 0.00 & 125.00 & $9.25^{c, d}$ & 0.88 & 24.33 \\
\hline$E_{2}$ & 0.00 & 35.91 & $0.05^{a, c}$ & 0.00 & 1.38 \\
\hline$E_{3}$ & 0.00 & 11.70 & $0.40^{b, d}$ & 0.03 & 4.00 \\
\hline \multicolumn{6}{|c|}{ Group B: fluoride varnish } \\
\hline$E_{0}$ & 0.01 & 84.00 & $4.00^{a, b}$ & 0.80 & 8.80 \\
\hline$E_{1}$ & 0.00 & 78.30 & $12.40^{c, d}$ & 1.60 & 23.80 \\
\hline$E_{2}$ & 0.00 & 2.83 & $0.00^{\mathrm{a}, \mathrm{c}, \mathrm{e}}$ & 0.00 & 0.65 \\
\hline$E_{3}$ & 0.00 & 14.10 & $0.80^{b, d, e}$ & 0.02 & 3.25 \\
\hline \multicolumn{6}{|c|}{ Group C: I\% CHX } \\
\hline$E_{0}$ & 0.00 & 27.40 & $4.30^{a, b}$ & 0.70 & 9.90 \\
\hline$E_{1}$ & 0.00 & 37.50 & $9.10^{\mathrm{c}, \mathrm{d}}$ & 1.80 & 14.80 \\
\hline$E_{2}$ & 0.00 & 5.92 & $0.26^{\mathrm{a}, \mathrm{c}}$ & 0.00 & 1.02 \\
\hline$E_{3}$ & 0.00 & 20.70 & $0.30^{b, d}$ & 0.09 & 4.70 \\
\hline \multicolumn{6}{|c|}{ Group D: $40 \% \mathrm{CHX}$} \\
\hline$E_{0}$ & 0.06 & 25.20 & $2.40^{a, b}$ & 0.33 & 13.50 \\
\hline$E_{1}$ & 0.00 & 76.90 & $8.10^{c, d}$ & 4.40 & 19.55 \\
\hline$E_{2}$ & 0.00 & 12.53 & $0.24^{a, c}$ & 0.00 & 1.97 \\
\hline$E_{3}$ & 0.00 & 5.00 & $0.50^{b, d}$ & 0.08 & 2.55 \\
\hline
\end{tabular}

Values with the same superscript letter ( $a, b, c, d, e)$ within a group were significantly different $(P<0.05)$.

surfaces supragingivally ${ }^{5,6}$ and exposing them to carious insults.

Recessions subsequent to the healing of inflamed gingival tissues in patients undergoing periodontal therapy predispose these patients to root caries. In addition to the control of periodontal pathogens, prevention of root caries in this patient population is crucial to maintaining oral health. In the present study, we compared the efficacy of preventive measures in relation to decreases in MS, ACC, and LB counts.

Fluoride and $\mathrm{CHX}$ are known to prevent caries and differ in their respective mechanisms of action. The caries-preventive effect of fluoride mainly is attributed to the effects on demineralization/remineralization at the tooth and oral fluids interface. ${ }^{29}$ Lesions, which have advanced into the dentin and are visible as white spots, can be remineralized with fluoride. ${ }^{30-32}$ Mechanistically, fluoride replaces protons $\left(\mathrm{H}^{+}\right.$ions) from the demineralized hydroxyapatite, which allows calcium to re-embed into apatite. ${ }^{33}$ In vitro enamel remineralization experiments demonstrated that with increasing concentrations of fluoride, the calcium loss from enamel was reversed under acidic conditions. ${ }^{34}$ When patients with carious lesions used toothpaste 
Table 3.

\section{Percentage of $A C C$ of Total Cultivable Microbiota}

\begin{tabular}{|c|c|c|c|c|c|}
\hline$A C C$ & Minimum & Maximum & Median & $\begin{array}{c}25 \% \\
\text { Percentile }\end{array}$ & $\begin{array}{c}75 \% \\
\text { Percentile }\end{array}$ \\
\hline \multicolumn{6}{|c|}{ Group A: control } \\
\hline$E_{0}$ & 0.20 & 78.50 & $18.10^{\mathrm{a}, \mathrm{b}, \mathrm{c}}$ & | 1.88 & 33.55 \\
\hline$E_{1}$ & 0.00 & 19.10 & $1.30^{\mathrm{a}, \mathrm{d}}$ & 0.00 & 2.50 \\
\hline$E_{2}$ & 0.00 & 2.38 & $0.00^{b, d}$ & 0.00 & 0.84 \\
\hline$E_{3}$ & 0.00 & 6.90 & $0.30^{c}$ & 0.00 & 1.75 \\
\hline \multicolumn{6}{|c|}{ Group B: fluoride varnish } \\
\hline$E_{0}$ & 0.50 & 81.60 & $19.30^{\mathrm{a}, \mathrm{b}, \mathrm{c}}$ & 9.93 & 41.80 \\
\hline$E_{1}$ & 0.00 & 30.00 & $0.90^{\mathrm{a}, \mathrm{d}}$ & 0.01 & 3.40 \\
\hline$E_{2}$ & 0.00 & $|0.3|$ & $0.00^{b, d}$ & 0.00 & 0.24 \\
\hline$E_{3}$ & 0.00 & 21.70 & $0.20^{c}$ & 0.00 & 4.65 \\
\hline \multicolumn{6}{|c|}{ Group C: I\% CHX } \\
\hline$E_{0}$ & 0.10 & 75.90 & $10.70^{a, b, c}$ & 3.10 & 20.35 \\
\hline$E_{1}$ & 0.00 & 47.10 & $0.40^{\mathrm{a}, \mathrm{d}}$ & 0.00 & 1.70 \\
\hline$E_{2}$ & 0.00 & 8.14 & $0.01^{b, d, e}$ & 0.00 & 0.10 \\
\hline$E_{3}$ & 0.00 & 18.70 & $0.30^{c, e}$ & 0.00 & 4.15 \\
\hline \multicolumn{6}{|c|}{ Group D: 40\% CHX } \\
\hline$E_{0}$ & 0.00 & 79.20 & $14.10^{\mathrm{a}, \mathrm{b}, \mathrm{c}}$ & 1.65 & 24.80 \\
\hline$E_{1}$ & 0.00 & 7.80 & $0.70^{a, d}$ & 0.00 & 2.80 \\
\hline$E_{2}$ & 0.00 & 6.63 & $0.00^{b, d, e}$ & 0.00 & 0.05 \\
\hline$E_{3}$ & 0.00 & 11.50 & $0.04^{\mathrm{c}, \mathrm{e}}$ & 0.00 & 1.75 \\
\hline
\end{tabular}

Values with the same superscript letter $(\mathrm{a}, \mathrm{b}, \mathrm{c}, \mathrm{d}, \mathrm{e})$ within a group were significantly different $(P<0.05)$.

with 1,000 parts per million (ppm) of fluoride, active root surface caries converted into inactive caries as a response to oral hygiene. ${ }^{28}$

The major benefit of chlorhexidine digluconate is its antimicrobial activity on $M S,{ }^{35}$ which is considered to initiate primary carious lesions ${ }^{36,37}$ and recurrent caries. ${ }^{38,39}$ As reviewed by Emilson, ${ }^{40}$ several clinical trials demonstrated the efficacy of CHX in caries prevention. The concentration of CHX and the frequency of applications are the determining factors for longterm effects. The number of retention sites from which MS gradually recolonizes affects the success of $\mathrm{CHX}$ treatment negatively. ${ }^{41-43}$

Patients in a periodontal maintenance phase were enrolled in the present study, and exposed facial root surfaces were selected based on their susceptibility to caries and their accessibility. ${ }^{21}$ One tooth per quadrant was selected to minimize interactions between different agents.

The plaque sampling was standardized for the individual build-up of mature plaque within 48 hours. Our primary goal was to obtain a plaque sample standardized in quantity and quality. However, the amount of plaque collected with a curet in one stroke varied. This may have affected the bacterial counts because
Table 4.

\section{Percentage of $L B$ of Total Cultivable Microbiota}

\begin{tabular}{|c|c|c|c|c|c|}
\hline$\angle B$ & Minimum & Maximum & Median & $\begin{array}{c}25 \% \\
\text { Percentile }\end{array}$ & $\begin{array}{c}75 \% \\
\text { Percentile }\end{array}$ \\
\hline \multicolumn{6}{|c|}{ Group A: control } \\
\hline$E_{0}$ & 0.01 & 106.50 & $0.30^{a, b, c}$ & 0.03 & 1.20 \\
\hline$E_{1}$ & 0.00 & 5.60 & $0.00^{\mathrm{a}, \mathrm{d}}$ & 0.00 & 0.02 \\
\hline$E_{2}$ & 0.00 & 0.17 & $0.00^{\mathrm{b}, \mathrm{d}, \mathrm{e}}$ & 0.00 & 0.00 \\
\hline$E_{3}$ & 0.00 & 5.00 & $0.00^{\mathrm{c}, \mathrm{e}}$ & 0.00 & 0.14 \\
\hline \multicolumn{6}{|c|}{ Group B: fluoride varnish } \\
\hline$E_{0}$ & 0.00 & 20.90 & $0.20^{a, b}$ & 0.05 & 1.35 \\
\hline$E_{1}$ & 0.00 & 25.60 & $0.02^{c, d}$ & 0.00 & 0.30 \\
\hline$E_{2}$ & 0.00 & 0.95 & $0.00^{a, c}$ & 0.00 & 0.00 \\
\hline$E_{3}$ & 0.00 & 2.80 & $0.00^{b, d}$ & 0.00 & 0.04 \\
\hline \multicolumn{6}{|c|}{ Group C: I\% CHX } \\
\hline$E_{0}$ & 0.00 & 12.00 & $0.10^{a, b, c}$ & 0.06 & 1.00 \\
\hline$E_{1}$ & 0.00 & 8.30 & $0.00^{\mathrm{a}, \mathrm{d}}$ & 0.00 & 0.02 \\
\hline$E_{2}$ & 0.00 & 0.01 & $0.00^{b, d, e}$ & 0.00 & 0.00 \\
\hline$E_{3}$ & 0.00 & 9.90 & $0.00^{\mathrm{c}, \mathrm{e}}$ & 0.00 & 0.02 \\
\hline \multicolumn{6}{|c|}{ Group D: $40 \% \mathrm{CHX}$} \\
\hline$E_{0}$ & 0.00 & 14.80 & $0.10^{a, b, c}$ & 0.01 & 0.70 \\
\hline$E_{1}$ & 0.00 & 0.50 & $0.00^{\mathrm{a}, \mathrm{d}}$ & 0.00 & 0.02 \\
\hline$E_{2}$ & 0.00 & 0.00 & $0.00^{b, d, e}$ & 0.00 & 0.00 \\
\hline$E_{3}$ & 0.00 & 0.60 & $0.00^{c, e}$ & 0.00 & 0.01 \\
\hline
\end{tabular}

Values with the same superscript letter (a, b, c, d, e) within a group were significantly different $(P<0.05)$.

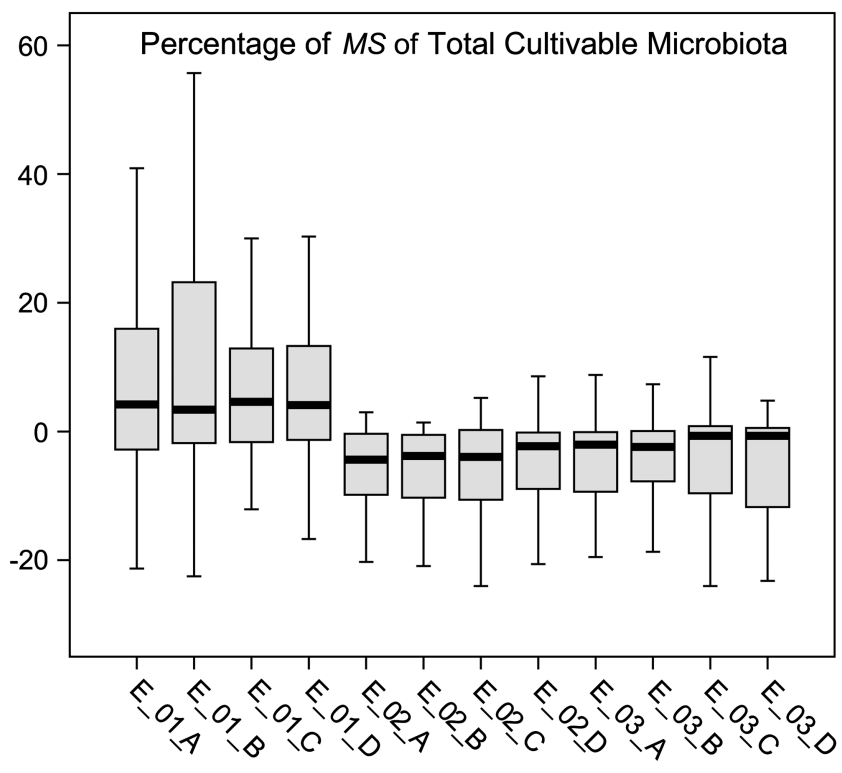

Figure 5.

The percentage of MS of total cultivable microbiota: differences between baseline and I year after examination (E_OI), between baseline and 2 years after examination (E_02), and between baseline and 3 years after examination (E_03) for groups A through $D$ (no significance). 


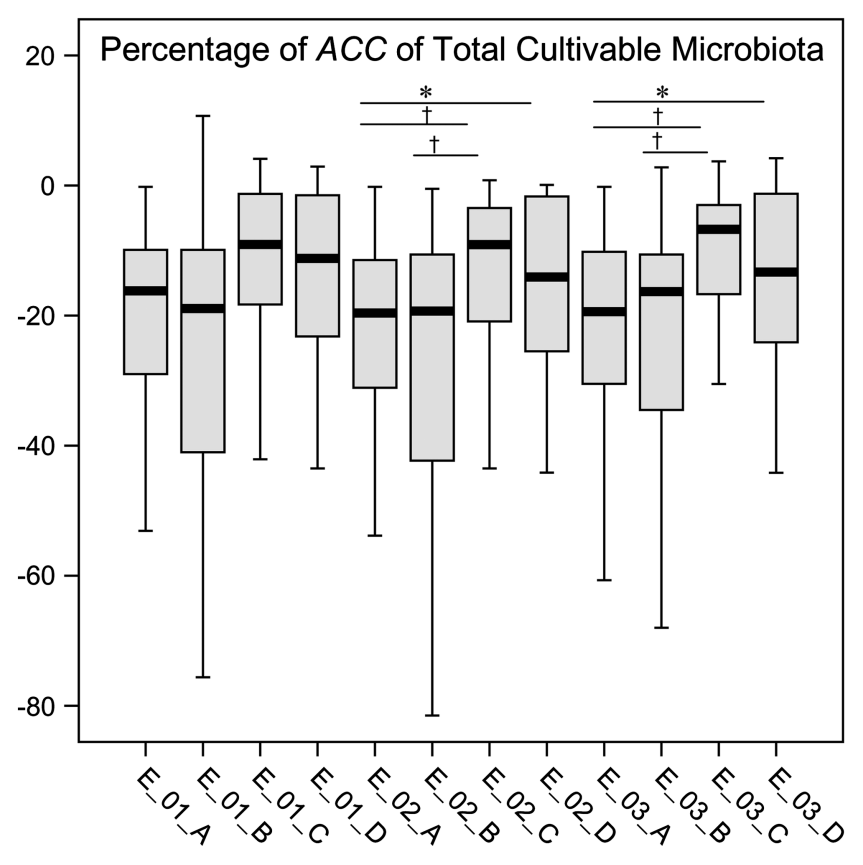

Figure 6.

The percentage of ACC of total cultivable microbiota: differences between baseline and I year after examination (E_OI), between baseline and 2 years after examination (E_02), and between baseline and 3 years after examination (E_03) for groups A through D. $* \mathrm{P}<0.01$; ${ }^{\dagger} \mathrm{P}<0.05$.

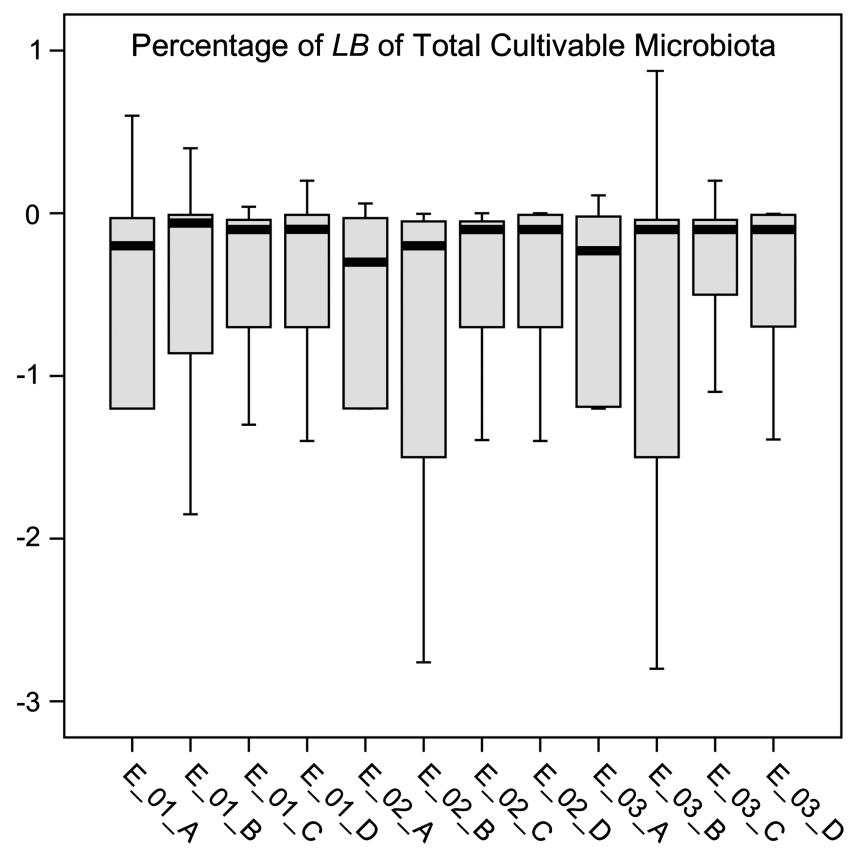

Figure 7.

The percentage of $\mathrm{LB}$ (lactobacilli) of total cultivable microbiota: differences between baseline and I year after examination (E_OI), between baseline and 2 years after examination (E_02), and between baseline and 3 years after examination (E_03) for groups A through D (no significance). they were evaluated as proportions of the bacteria harvested. ${ }^{20}$

The varnishes to be tested were applied every 3 months for 3 years. The active components were $1 \% \mathrm{CHX}$ and $1 \%$ thymol, $40 \% \mathrm{CHX}$, and 22,600 ppm sodium fluoride. The baseline percentages of $M S, L B$, and $A C C$ in the total cultivable microbiota were significantly different compared to the percentages after 3 years for all groups. Regardless of the concentration of the CHX preparations, bacterial numbers were reduced significantly. Previous clinical studies using CHX to prevent caries in fissures compared different CHX concentrations. Forty-percent CHX varnish was most effective for MS in human dental plaque in fissures compared to $10 \%$ or $20 \%$ CHX varnishes. ${ }^{44}$ This varnish with the highest CHX concentration also was effective in preventing demineralization in vitro when enamel and dentin specimens were challenged with MS suspensions. ${ }^{45}$ In contrast, in the present study on root caries, the concentration of the CHX varnish (10\% versus $40 \%$ ) did not affect the counts of MS, $L B$, and ACC when applied at 3-month intervals during the 3-year study period.

The $1 \%$ CHX varnish also contained $1 \%$ thymol as an active antimicrobial agent. Although thymol by itself was shown to inhibit the total growth of Actinomyces naeslundii in $30 \%$ to $50 \%$ of the patients, ${ }^{46}$ it had no noticeable effect on MS or $L B$. This finding was confirmed in our study in the group treated with $1 \% \mathrm{CHX}$. Another in vitro study showed that thymol was active against different Gram-positive and Gram-negative bacterial strains as well as yeast. ${ }^{47}$

In a population of low-income older adults, CHX was used as a preventive measure; it had similar effects on the root caries development as found in our study. The incidence of root caries was reduced to a statistically non-significant level when a group receiving a weekly application of $0.12 \% \mathrm{CHX}$ rinse and a fluoride varnish was compared to another group receiving "conventional" care from private dental practitioners. ${ }^{48}$

Fluoride delivered as a rinse and toothpaste has been tested for the prevention of root caries. The fluoride rinse was a convenient and efficient approach in controlling the prevalence of root caries in elderly populations. ${ }^{14}$ However, the use of a fluoride dentifrice and a fluoride rinse was not sufficient to prevent new root caries in periodontal maintenance patients. ${ }^{49}$ About $90 \%$ of the subjects developed at least one new root caries lesion during the 2-year study period. ${ }^{49}$ In contrast, no root caries developed during the 3 years in the present study.

Dental plaque matures via a succession of certain bacterial species into a biofilm. Initially, early colonizers, such as ACC species, localize at the root surface via pellicle facilitated by intrageneric coaggregation. ${ }^{50}$ 
The established ACC promote the colonization of Streptococcus species. ${ }^{51}$ The microbiota at the root surface form multiple coaggregations leading to the formation of a biofilm on the root surface. ${ }^{52}$ In particular, the metabolism of $M S, L B$, and $A C C$ seems to act synergistically, promoting each others' growth and culminating in increased acidogenicity. ${ }^{53}$ During the instrumentation of the tooth and root surfaces, the colonization of dental plaque is disrupted and removed from supragingival and subgingival surfaces. In our study, the efficiency of mechanical prophylaxis was demonstrated by a reduction in the baseline percentages of $M S, L B$, and ACC in the total cultivable microbiota in contrast to the corresponding percentages at the final examination for all groups. The increase in MS after 1 year might indicate a microbial shift from predominantly periopathogenic to predominantly cariogenic pathogens. A rigorous periodontal maintenance program seemed to promote the growth of $M S$ in the first year. Similar results were found after initial periodontal therapy. ${ }^{54}$ However, at the final examination, oral hygiene levels and bacterial counts were equally good when mechanical plaque removal alone was compared to adjunctive CHX or fluoride application. The major factor critical to an increased risk for root caries is the accumulation of plaque due to poor oral hygiene ${ }^{55-57}$ or erratic compliance with periodontal maintenance. ${ }^{58}$ In the present study, the oral hygiene levels of the patients improved continuously over the 3-year duration of the study. In addition, they received professional plaque control measures every 3 months. Neither root nor coronal caries developed de novo during the study period. The efficiency of plaque control on caries development is known from a long-term study of 30 years. ${ }^{59}$ Patients with the highest risk for caries or periodontal disease returned every 3 months for the preventive program and experienced an average of only 2.1 new carious lesions.

\section{CONCLUSIONS}

Regular professional tooth cleaning, oral hygiene instructions at 3-month intervals, and good oral home care might be sufficient to control the cariogenic microbiota in patients with completed non-surgical therapy (scaling and root planing). Adjunctive chemotherapeutic agents, such as fluoride or CHX, did not provide an additional benefit over home care and professional oral hygiene procedures.

\section{ACKNOWLEDGMENTS}

The authors thank Prof. J.-F. Roulet, formerly of the Department of Operative and Preventive Dentistry, Charité - University Medical School of Berlin, for his thoughts on the study design. Prof. H. Lang, Department of Operative and Preventive Dentistry and
Endodontics, Section of Periodontology, HeinrichHeine-University, contributed to the discussion of the manuscript. This study was supported by two companies: Vivadent-Vivacare, Schaan, Liechtenstein (1\% CHX and saliva tests) and GABA, Basel, Switzerland (toothpaste).

\section{REFERENCES}

1. Griffin SO, Griffin PM, Swann JL, Zlobin N. Estimating rates of new root caries in older adults. J Dent Res 2004;83:634-638.

2. Hix JO, O'Leary TJ. The relationship between cemental caries, oral hygiene status and fermentable carbohydrate intake. J Periodontol 1976;47:398-404.

3. Ravald N, Hamp SE. Prediction of root surface caries in patients treated for advanced periodontal disease. $J$ Clin Periodontol 1981;8:400-414.

4. Keltjens H, Schaeken T, van der Hoeven H, Hendriks $\mathrm{J}$. Epidemiology of root surface caries in patients treated for periodontal diseases. Community Dent Oral Epidemiol 1988;16:171-174.

5. Ravald N, Hamp SE, Birkhed D. Long-term evaluation of root surface caries in periodontally treated patients. J Clin Periodontol 1986;13:758-767.

6. Katz RV, Hazen SP, Chilton NW, Mumma RD Jr. Prevalence and intraoral distribution of root caries in an adult population. Caries Res 1982;16:265-271.

7. Jordan HV, Hammond BF. Filamentous bacteria isolated from human root surface caries. Arch Oral Biol 1972;17:1333-1342.

8. Summney DL, Jordan HV. Characterization of bacteria isolated from human root surface caries. J Dent Res 1974;53:343-351.

9. Syed SA, Loesche WJ, Pape HL Jr., Grenier E. Predominant cultivable flora isolated from human root surface caries plaque. Infect Immun 1975;11:727-731.

10. Emilson CG, Klock B, Sanford CB. Microbial flora associated with presence of root surface caries in periodontally treated patients. Scand JDentRes 1988;96:40-49.

11. Bowden GH, Ekstrand J, McNaughton B, Challacombe SJ. Association of selected bacteria with the lesions of root surface caries. Oral Microbiol Immunol 1990;5: 346-351.

12. Lynch E, Beighton D. A comparison of primary root caries lesions classified according to colour. Caries Res 1994;28:233-239.

13. Hunt RJ, Eldredge JB, Beck JD. Effect of residence in a fluoridated community on the incidence of coronal and root caries in an older adult population. $J$ Public Health Dent 1989;49:138-141.

14. Wallace MC, Retief DH, Bradley EL. The 48-month increment of root caries in an urban population of older adults participating in a preventive dental program. J Public Health Dent 1993;53:133-137.

15. Lynch E, Baysan A, Ellwood R, Davies R, Petersson L, Borsboom P. Effectiveness of two fluoride dentifrices to arrest root carious lesions. Am J Dent 2000;13: 218-220.

16. Sandham HJ, Brown J, Chan KH. Clinical elimination of Streptococcus mutans with Chlorzoin and polyurethane varnishes. J Dent Res 1991;70:1401-1408.

17. Schaeken MJ, van der Hoeven JS, Hendriks JC. Effects of varnishes containing chlorhexidine on the human dental plaque flora. J Dent Res 1989;68:17861789. 
18. Weiger R, Friedrich C, Netuschil L, Schlagenhauf U. Effect of chlorhexidine-containing varnish (Cervitec) on microbial vitality and accumulation of supragingival dental plaque in humans. Caries Res 1994;28:267-271.

19. Bratthall D, Serinirach R, Rapisuwon S, et al. A study into the prevention of fissure caries using an antimicrobial varnish. Int Dent J 1995;45:245-254.

20. Van Houte J, Lopman J, Kent R. The predominant cultivable flora of sound and carious human root surfaces. J Dent Res 1994;73:1727-1734.

21. Ekenback SB, Linder LE, Lonnies H. Effect of four dental varnishes on the colonization of cariogenic bacteria on exposed sound root surfaces. Caries Res 2000;34:70-74.

22. Syed SA, Loesche WJ. Survival of human dental plaque flora in various transport media. Appl Microbiol 1972;24:638-644.

23. Zylber LJ, Jordan HV. Development of a selective medium for detection and enumeration of Actinomyces viscosus and Actinomyces naeslundii in dental plaque. J Clin Microbiol 1982;15:253-259.

24. Gold OG, Jordan HV, Van Houte J. A selective medium for Streptococcus mutans. Arch Oral Biol 1973;18:1357-1364.

25. Lange DE, Plagmann HC, Eenboom A, Promesberger A. Clinical methods for the objective evaluation of oral hygiene (in German). Dtsch Zahnarztl Z 1977;32: 44-47.

26. Turesky S, Gilmore ND, Glickman I. Reduced plaque formation by the chloromethyl analogue of vitamin C. $J$ Periodontol 1970;41:41-43.

27. Saxer UP, Mühlemann HR. Motivation and education (in German). SSO Schweiz Monatsschr Zahnheilkd 1975;85:905-919.

28. Nyvad B, Fejerskov O. Active root surface caries converted into inactive caries as a response to oral hygiene. Scand J Dent Res 1986;94:281-284.

29. Addy $M$, Newcombe RG. Statistical versus clinical significance in periodontal research and practice. Periodontol 2000 2005;39:132-144.

30. ten Cate JM. Current concepts on the theories of the mechanism of action of fluoride. Acta Odontol Scand 1999;57:325-329.

31. Itthagarun A, Wei SH, Wefel JS. The effect of different commercial dentifrices on enamel lesion progression: An in vitro pH-cycling study. Int Dent $J$ 2000;50: 21-28.

32. Wefel JS, Jensen ME, Triolo PT, Faller RV, Hogan MM, Bowman WD. De/remineralization from sodium fluoride dentifrices. Am J Dent 1995;8:217-220.

33. König KG. Caries and Caries Prevention (in German). Stuttgart, Germany: Thieme; 1987:60-80.

34. ten Cate JM, Duijsters PPE. Influence of fluoride in solution on tooth demineralization. Caries Res 1983;17: 193-199.

35. Emilson CG. Effect of chlorhexidine gel treatment on Streptococcus mutans population in human saliva and dental plaque. Scand J Dent Res 1981;89:239-246.

36. Emilson CG, Krasse B. Support for and implications of the specific plaque hypothesis. Scand J Dent Res 1985;93:96-104.

37. Loesche WJ. Role of Streptococcus mutans in human dental decay. Microbiol Rev 1986;50:353-380.

38. Svanberg M, Jacobson C, Hager B. Streptococcus mutans, lactobacilli and Streptococcus sanguis in plaque from abutment teeth of cemented and of loose retainers. Caries Res 1987;21:474-480.
39. Bentley CD, Broderius CA, Drake CW, Crawford JJ. Relationship between salivary levels of mutans streptococci and restoration longevity. Caries Res 1990;24:298-300.

40. Emilson CG. Potential efficacy of chlorhexidine against mutans streptococci and human dental caries. J Dent Res 1994;73:682-691.

41. Maltz M, Zickert I, Krasse B. Effect of intensive treatment with chlorhexidine on number of Streptococcus mutans in saliva. Scand J Dent Res 1981;89:445-449.

42. Sandham HJ, Brown J, Phillips HI, Chan KH. A preliminary report of long-term elimination of detectable mutans streptococci in man. J Dent Res 1988;67:9-14.

43. Sandham HJ, Brown J, Chan KH, Phillips HI, Burgess RC, Stokl AJ. Clinical trial in adults of an antimicrobial varnish for reducing mutans streptococci. J Dent Res 1991;70:1401-1408.

44. Christgau M, Manner T, Beuer S, Hiller KA, Schmalz G. Periodontal healing after non-surgical therapy with a modified sonic scaler: A controlled clinical trial. J Clin Periodontol 2006;33:749-758.

45. van Loveren C, Buijs JF, Buijs MJ, ten Cate JM Protection of bovine enamel and dentine by chlorhexidine and fluoride varnishes in a bacterial demineralization model. Caries Res 1996;30:45-51.

46. Evans RT, Baker PJ, Coburn RA, Fischmann SL, Genco RJ. In vitro antiplaque effects of antiseptic phenols. J Periodontol 1977;48:156-162.

47. Petersson LG, Edwardsson S, Arends J. Antimicrobial effect of a dental varnish, in vitro. Swed Dent J 1992; 16:183-189.

48. Powell LV, Persson RE, Kiyak HA, Hujoel PP. Caries prevention in a community-dwelling older population. Caries Res 1999;33:333-339.

49. Paraskevas S, Danser MM, Timmerman MF, van der Velden U, van der Weijden GA. Amine fluoride/stannous fluoride and incidence of root caries in periodontal maintenance patients. A 2 year evaluation. J Clin Periodontol 2004;31:965-971.

50. Kolenbrander PE, Andersen RN, Moore LV. Intrageneric coaggregation among strains of human oral bacteria: Potential role in primary colonization of the tooth surface. Appl Environ Microbiol 1990;56:38903894.

51. Cisar JO, Kolenbrander PE, McIntire FC. Specificity of coaggregation reactions between human oral streptococci and strains of Actinomyces viscosus or Actinomyces naeslundii. Infect Immun 1979;24:742-752.

52. Shen S, Samaranayake LP, Yip HK. Coaggregation profiles of the microflora from root surface caries lesions. Arch Oral Biol 2005;50:23-32.

53. Shen S, Samaranayake LP, Yip HK. In vitro growth, acidogenicity and cariogenicity of predominant human root caries flora. J Dent 2004;32:667-678.

54. Quirynen M, Gizani S, Mongardini C, Declerck D, Vinckier F, Van Steenberghe D. The effect of periodontal therapy on the number of cariogenic bacteria in different intra-oral niches. J Clin Periodontol 1999;26:322-327.

55. Kitamura M, Kiyak HA, Mulligan K. Predictors of root caries in the elderly. Community Dent Oral Epidemiol 1986; 14:34-38.

56. Lohse WG, Carter HG, Brunelle JA. The prevalence of root surface caries in a military population. Mil Med 1977; 142:700-703.

57. Reiker J, van der Velden U, Barendregt DS, Loos BG. A cross-sectional study into the prevalence of root caries in periodontal maintenance patients. J Clin Periodontol 1999;26:26-32. 
58. Pepelassi E, Tsami A, Komboli M. Root caries in periodontally treated patients in relation to their compliance with suggested periodontal maintenance intervals. Compend Contin Educ Dent 2005;26:835844.

59. Axelsson P, Nystrom B, Lindhe J. The long-term effect of a plaque control program on tooth mortality, caries and periodontal disease in adults. Results after 30 years of maintenance. J Clin Periodontol 2004;31:749-757.
Correspondence: Dr. M. Bizhang, Department of Operative and Preventive Dentistry and Endodontics, Section of Periodontology, Heinrich-Heine-University, Mooren Str. 5, Building 18.13, D-40225 Düsseldorf, Germany. Fax: 49-211-81-18201; e-mail: mozhgan.bizhang@med. uni-duesseldorf.de.

Submitted November 16, 2006; accepted for publication February 20, 2007. 